\title{
Adipose-Derived Mesenchymal Stem Cells as the Panacea for Degenerative Joint Diseases: Fact or Fiction?
}

\author{
Lo Presti Mirco*, Costa Giuseppe Gianluca, Vasco Cosimo, Agrò Giuseppe and Zaffagnini \\ Stefano \\ IRCCS Rizzoli Orthopedic Institute, Italy
}

*Corresponding author: Lo Presti Mirco, IRCCS Rizzoli Orthopedic Institute, Via di Barbiano n. 1/10, 40136, Bologna, Italy

\section{ARTICLE INFO \\ Received: 幽 August 31, 2019 \\ Published: 慧 September 10, 2019}

Citation: Lo Presti Mirco, Costa Giuseppe Gianluca, Vasco Cosimo, Agrò Giuseppe and Zaffagnini Stefano. Adipose-Derived Mesenchymal Stem Cells as the Panacea for Degenerative Joint Diseases: Fact or Fiction?. Biomed J Sci \& Tech Res 21(2)2019. BJSTR. MS.ID.003577.

\begin{abstract}
The biological approaches have recently gained more attention among orthopedics clinicians and surgeons, and in particular adipose-derived mesenchymal stem cells (AMSCs), due to the invasiveness of the procedure and the good outcomes reported in preliminary trials. In Literature, more than 5,000 articles dealing with the potentialities of ADSC are currently available, but, in our acknowledgement, only few papers focused on clinical results, with contradictory results. In addition, concerns about safety remain among clinicians, because the follow-up time in these analyses was yet limited and a chance of considerable risk is still possible. Nonetheless, long-term adverse events are still poorly researched. As a result, it is impossible to draw a conclusive sentence due to the short follow-up time or small sample size. More high-quality studies should be performed to validate safety of this fascinating approach, first, and then efficacy.
\end{abstract}

Keywords: Adipose-Derived Stem Cells; Stromal Vascular Factor; Cartilage; Osteoarthritis; Degenerative Joint Disease

Abbreviations: HA: Hyaluronic Acid; MSCs: Mesenchymal Stem Cells; GF: Growth Factors; AMSCs: Adipose-Derived Mesenchymal Stem Cells; IL: Interleukin; SVF: Stromal Vascular Fraction; MRI: Magnetic Resonance Imaging

\section{Introduction}

The continuously evolving society of the third millennium requires more and more athletic skills for citizens of all countries. Given the increasing life expectancy, together with the global trend to obesity and the increasing number of sport-related injuries at all ages, degenerative joint pathologies are becoming an enormous medical and socio-economic burden [1]. Non-surgical treatments, such as physio kinesitherapy, pharmacological treatments, hyaluronic acid (HA) or its derivatives, temporarily target the symptoms but cannot prevent the degenerative process [2]. Jointpreserving surgical treatments, such as arthroscopic shaving, provide temporary relief of symptoms [3]. In this context, the biological approaches have recently gained more attention among orthopedics clinicians and surgeons, and in particular mesenchymal stem cells (MSCs), for their ability to act not only on cartilage, but on the whole joint environment [4]. Initially, MSCs were described by Caplan [5] as pluripotent cells, easily isolated from different tissues (including bone marrow, adipose tissue, synovial capsule), which can differentiate into different cell lineages (such as bone, cartilage, muscle, and tendons), contributing in this way to repair the damaged area.

More recently, several clinicians emphasized their paracrine effect to secret various cytokines and growth factors (GF) to adjacent cells, leading to vascularization and cellular proliferation in damaged tissues, and their immunomodulatory properties, so they can reduce inflammation in injured tissues [4]. The definition of Medicinal Signaling Cells, proposed by the same Caplan, represents a more comprehensive attempt to describe the potential of this issue, however not yet fully clarified [6]. Adipose-derived 
mesenchymal stem cells (AMSCs), firstly identified in the early 2000s [7], offer some intrinsic advantages that deserves particular attention; AMSCs are easily harvested from subcutaneous tissue in large quantities, with low morbidity of the patients, and can easily be isolated and expanded in vitro [8-11]. Moreover, AMSCs have been shown to be immunoprivileged, with low risk of rejection, and more genetically stable in long term culture, with a greater proliferative rate than MSCs isolated from other tissues, in particular bone marrow [12-15].

In addition, AMSCs induce a trophic effect through the secretion of a large number of GF and anti-inflammatory proteins in response to inflammatory molecules, including prostaglandin 2 , hepatocyte growth factor, transforming growth factor- $\beta 1$, vascular endothelial growth factor, tumor necrosis factor- $\alpha$, stromal cellderived factor-1, nitrous oxide, IL (interleukin)-4, IL-6, IL-10, and IL-1 receptor antagonist, that support the angiogenesis, tissue remodeling, and antiapoptotic events [16-18]. However, the real potential of these cells remains unknown, since culture expanded AMSC are usually considered to be a pharmaceutical product requiring government regulatory clearance; due to such government regulatory issues, stromal vascular fraction (SVF) has been more commonly used for various orthopedic applications in clinical settings, representing a further confounding variable. The SVF is obtained after an enzymatic or mechanic process [19], and contains a heterogeneous population of cell types, including preadipocytes, pericytes, monocytes, macrophages, red blood cells, and other adventitial stromal cells $[20,21]$, as well as AMSCs, which account for $30 \%$ of the total SVF cells [22].

If the therapeutic properties can be attributed to AMSCs or the surrounding perivascular environment is unclear, but some studies have shown improved results with the application of SVF compared to AMSCs, promoting cartilage and subchondral bone regeneration [23] and forming new cartilage matrix [24]. However, further investigations are required to validate these exciting preclinical results for the application in the clinical practice. During the last years, the clinical potential of AMSCs in the treatment of degenerative joint diseases has been reported in several studies, with conflicting findings. Consequently, the aim of the present study is to review the clinical outcomes of AMSCs (including clinical trials where SVF was under investigation) for the treatment of degenerative joint diseases.

\section{Clinical Results}

In Literature, more than 5,000 articles dealing with the potentialities of ADSC are currently available, but, in our acknowledgement, only 23 papers [25-47] are clinical trials focusing on clinical and functional outcomes. Furthermore, only few papers present a high level of methodological quality $[26,31,40]$. In most cases, the clinical application of AMSCs was evaluated in the knee joint, but also in ankle [29,33] and hip [27,37] was tested. AMSCs (or SVF) was harvested from abdominal fat in all but two studies, where the harvest site was the infrapatellar fat pad [35] and the buttock [38]. The clinical effect was evaluated as surgical adjuvant in 5 papers [26,29, 33, 40,41], and as injective approach in the other 18 papers [25,27,28,30-32,34-39,42-47]. In all studies, a significant improvement in clinical and functional scores from baseline to last follow up (from 6 months to 28.6 months) was reported; the beneficial effect seems to reach the highest point between 6 months and 1 year of follow up $[25,27,34,43,46]$, but a decreasing trend was recorded at longer follow up [30]. Among the 6 comparative studies, the most significant difference when compared to control group, was recorded for pain relief $[26,31,35,40]$, whereas contradictory functional results were recorded, with better functional scores described in 3 papers [29,31,33], no significant intergroup difference in 2 papers $[35,40]$, and even better functional score in the control group in 1 paper [26].

Predictors of poorer results were greater lesion size [39], body mass index [39] and lower preoperative pain [47]. The effect on cartilage was assessed thanks to magnetic resonance imaging (MRI) or second-look arthroscopy in 20 papers, with significant improvement in all but 3 papers, where worse or unchanged findings were reported in most of patients treated $[39,40,46]$. As a result, it is impossible to draw a conclusive sentence due to the short followup time or small sample size. Contradictory results, heterogeneity in outcome measures, heterogeneity in co-interventions (such as surgery, HA or GF injections), processing methods and injection frequency and timing make it difficult to obtain a general and unambiguous statement among clinicians. In addition, concerns about safety remain among clinicians. Two systematic reviews of clinical trials (including case series) evaluating MSCs administered both locally and systemically with follow-up of up to 75 months found no serious adverse events [48,49]. Moreover, currently, evidence of malignant transformation of MSCs is lacking [48]. It should, however, be noted that the follow-up time in these analyses was yet limited and a chance of considerable risk is still possible. Nonetheless, long-term adverse events are still poorly researched.

\section{Conclusion}

In conclusion, it is impossible with actual knowledge to identify the real potential of this fascinating possibility of therapy. Numerous studies are currently in progress to clarify questions that still remain unanswered, regarding the long-term durability of these procedures, the possible modifications that have to be done to achieve better results, and the best-performing biological agents for each given kind of patient and/or grade of disease. In the meanwhile, more high-quality studies should be performed to validate their safety, first, and then efficacy.

\section{References}

1. Litwic A, Edwards MH, Dennison EM, Cooper C (2013) Epidemiology and burden of osteoarthritis. Br Med Bull 105: 185-199.

2. McAlindon TE, Bannuru RR, Sullivan M, Arden NK, Berenbaum F, et al. (2014) OARSI guidelines for the nonsurgical management of knee osteoarthritis. Osteoarthr Cartil 22(3): 363-388. 
3. Redondo ML, Naveen NB, Liu JN, Tauro TM, Southworth TM, et al. (2018) Preservation of Knee Articular Cartilage. Sports Med Arthrosc Rev 26(4): $23-30$

4. Mancuso P, Raman S, Glynn A, Barry F, Murphy JM (2019) Mesenchymal Stem Cell Therapy for Osteoarthritis: The Critical Role of the Cell Secretome. Front Bioeng Biotechnol 7: 9.

5. Osdoby P, Caplan AI (1979) Osteogenesis in cultures of limb mesenchymal cells. Dev Biol 73(1): 84-102.

6. Murphy MB, Moncivais K, Caplan AI (2013) Mesenchymal stem cells: environmentally responsive therapeutics for regenerative medicine. Exp Mol Med 45: 54.

7. Murphy J, Fink D, Hunziker E, Barry F (2003) Stemcell therapy in a caprine model of osteoarthritis. Arthritis Rheum 48(12): 3464-3474.

8. Morcos MW, Al Jallad H, Hamdy R (2015) Comprehensive Review of Adipose Stem Cells and Their Implication in Distraction Osteogenesis and Bone Regeneration. Biomed Res Int 2015: 842975.

9. Aust L, Devlin B, Foster SJ, Halvorsen YDC, Hicok K, et al. (2004) Yield of human adipose-derived adult stem cells from liposuction aspirates. Cytotherapy 6(1): 7-14.

10. Rodriguez AM, Elabd C, Amri EZ, Ailhaud G, Dani C (2005) The human adipose tissue is a source of multipotent stem cells. Biochimie 87(1): 125-128.

11. Zhu Y, Liu T, Song K, Fan X, Ma X, et al. (2008) Adipose-derived stem cell: A better stem cell than BMSC. Cell Biochem. Funct 26(6): 664-675.

12. Bertozzi N, Simonacci F, Grieco MP, Grignani E, Raposio E (2017) The biological and clinical basis for the use of adipose-derived stem cells in the field of wound healing. Ann Med Surg 20: 41-48.

13. Daher SR, Johnstone BH, Phinney DG, March KL (2008) Adipose Stromal/ Stem Cells: Basic and Translational Advances: The IFATS Collection Introduction. Stem Cells 26(10): 2664-2665.

14. Gonzalez Rey E, Gonzalez MA, Varela N, O’Valle F, Hernandez Cortes P, et al. (2010) Human adipose-derived mesenchymal stem cells reduce inflammatory and $\mathrm{T}$ cell responses and induce regulatory $\mathrm{T}$ cells in vitro in rheumatoid arthritis. Ann. Rheum. Dis 69(1): 241-248.

15. Dahl J, Duggal S, Coulston N, Millar D, Melki J, et al. (2008) Genetic and epigenetic instability of human bone marrow mesenchymal stem cells expanded in autologous serum or fetal bovine serum. Int J Dev Biol 52(8): 1033-1042.

16. Djouad F, Bou C, Ghannam S, Noel D, Jorgensen C (2009) Mesenchymal stem cells: Innovative therapeutic tools for rheumatic diseases. Nat Rev Rheumatol 5(7): 392-399.

17. Kilroy GE, Foster SJ, Wu X, Ruiz J, Sherwood S, et al. (2007) Cytokine profile of human adipose-derived stem cells: Expression of angiogenic, hematopoietic, and pro-inflammatory factors. J Cell Physiol 212(3): 702 709.

18. Conese M, Carbone A, Castellani S, Di Gioia S (2013) Paracrine Effects and Heterogeneity of Marrow-Derived Stem/Progenitor Cells: Relevance for the Treatment of Respiratory Diseases. Cells Tissues Organs 197(6): 445-473.

19. Aronowitz JA, Lockhart RA, Hakakian CS (2015) Mechanical versus enzymatic isolation of stromal vascular fraction cells from adipose tissue. Springerplus 4: 713.

20. Zuk PA, Zhu M, Mizuno H, Huang J, Futrell JW, et al. (2001) Multilineage cells from human adipose tissue: implications for cell-based therapies. Tissue Eng 7(2):211-228.

21. Zuk PA, Zhu M, Ashjian P, De Ugarte DA, Huang JI, et al. (2002) Human adipose tissue is a source of multipotent stem cells. Mol Biol Cell 13(12): 4279-4295.

22. Bertozzi N, Simonacci F, Grieco MP, Grignaffini E, Raposio E (2017) The biological and clinical basis for the use of adipose-derived stem cells in the field of wound healing. Ann Med Surg 20: 41-48.
23. Jurgens WJ, Kroeze RJ, Zandieh Doulabi B, van Dijk A, Renders GA, et al. (2013) One-step surgical procedure for the treatment of osteochondral defects with adipose-derived stem cells in a caprine knee defect: A pilot study. Biores Open Access 2(4): 315-325.

24. Wu L, Prins H, Leijten J, Helder MN, Evseenko D, et al. (2016) Chondrocytes Cocultured with Stromal Vascular Fraction of Adipose Tissue Present More Intense Chondrogenic Characteristics Than with Adipose Stem Cells. Tissue Eng. Part A 22(3-4): 336-348.

25. Pers YM, Rackwitz L, Ferreira R, Pullig O, Delfour C, et al. (2016) Adipose mesenchymal stromal cell-based therapy for severe osteoarthritis of the knee: A phase I dose-escalation trial. Stem Cells Transl Med 5(7): $847-$ 856

26. Nguyen PD, Tran TD, Nguyen HT, Vu HT, Le PT, et al. (2017) Comparative clinical observation of arthroscopic microfracture in the presence and absence of a stromal vascular fraction injection for osteoarthritis. Stem Cells Transl Med 6(1): 187-195.

27. Pak J, Lee JH, Park KS, Lee SH (2017) Efficacy of autologous adipose tissue-derived stem cells with extracellular matrix and hyaluronic acid on human hip osteoarthritis. Biomed Res 28(4): 1654-1658.

28. Song Y, Du H, Dai C, Zhang L, Li S, et al. (2018) Human adipose-derived mesenchymal stem cells for osteoarthritis: A pilot study with long-term follow-up and repeated injections. Regen Med 13(3): 295-307.

29. Kim YS, Koh YG (2016) Injection of mesenchymal stem cells as a supplementary strategy of marrow stimulation improves cartilage regeneration after lateral sliding calcaneal osteotomy for varus ankle osteoarthritis: Clinical and second-look arthroscopic results. Arthroscopy 32(5): 878-889.

30. Jo $\mathrm{CH}$, Chai JW, Jeong EC, Oh S, Shin JS, et al. (2017) Intra-articular injection of mesenchymal stem cells for the treatment of osteoarthritis of the knee: A 2-year follow-up study. Am J Sports Med 45(12): 27742783.

31. Kuah D, Sivell S, Longworth T, James K, Guermazi A, et al. (2018) Safety, tolerability and efficacy of intra-articular progenza in knee osteoarthritis: A randomized double-blind placebo-controlled single ascending dose study. J Transl Med 16(1): 49.

32. Pak J, Lee JH, Park KS, Jeong BC, Lee SH (2016) Regeneration of cartilage in human knee osteoarthritis with autologous adipose tissue-derived stem cells and autologous extracellular matrix. Biores Open Access 5(1): 192-200.

33. Kim YS, Lee M, Koh YG (2016) Additional mesenchymal stem cell injection improves the outcomes of marrow stimulation combined with supramalleolar osteotomy in varus ankle osteoarthritis: Short-term clinical results with second-look arthroscopic evaluation. J Exp Orthop 3: 12 .

34. Fodor PB, Paulseth SG (2016) Adipose derived stromal cell (ADSC) injections for pain management of osteoarthritis in the human knee joint. Aesthet Surg J 36(2): 229-236.

35. Koh GY, Choi YJ (2012) Infrapatellar fat pad-derived mesenchymal stem cell therapy for knee osteoarthritis. Knee 19(6): 902-907.

36. Koh GY, Jo SB, Kwon OR, Suh DS, Lee SW, et al. (2013) Mesenchymal stem cell injections improve symptoms of knee osteoarthritis. Arthroscopy 29(4): 748-755

37. Pak J (2011) Regeneration of human bones in hip osteonecrosis and human cartilage in knee osteoarthritis with autologous adiposetissuederived stem cells: a case series. Journal of Medical Case Reports 5: 296

38. Koh YG, Choi YJ, Kwon SK, Kim YS, Yeo JE (2015) Clinical results and second-look arthroscopic findings after treatment with adipose-derived stem cells for knee osteoarthritis. Knee Surgery Sports Traumatology Arthroscopy 23(5): 1308-1316.

39. Koh YG, Choi YJ, Kwon OR, Kim YS (2014) Second-look arthroscopic evaluation of cartilage lesions after mesenchymal stem cell implantation in osteoarthritic knees. The American Journal of Sports Medicine 42(7): 1628-1637. 
40. Koh YG, Kwon OR, Kim YS, Choi YJ (2014) Comparative outcomes of open-wedge high tibial osteotomy with platelet rich plasma alone or in combination with mesenchymal stem cell treatment: a prospective study. Arthroscopy 30(11): 1453-1460.

41. Kim YS, Choi YJ, Suh DS, Heo DB, Kim YI, et al. (2015) Mesenchymal stem cell implantation in osteoarthritic knees: is fibrin glue effective as a scaffold? The American Journal of Sports Medicine 43(1): 176-185.

42. Jo CH, Lee YG, Shin WH, Kim H, Chai JW, et al (2014) Intra-articular injection of mesenchymal stem cells for the treatment of osteoarthritis of the knee: a proof-of-concept clinical trial. Stem Cells 32(5): 12541266.

43. Pak J, Lee JH, Lee SH (2014) Regenerative Repair of Damaged Meniscus with Autologous Adipose Tissue-Derived Stem Cells. Biomed Res Int 2014: 436029 .

44. Freitag J, Li D, Wickham J, Shah K, Tenen A (2017) Effect of autologous adipose-derived mesenchymal stem cell therapy in the treatment of a post-traumatic chondral defect of the knee. BMJ Case Rep 2017-220852.

45. Freitag J, Shah K, Wickham J, Boyd R, Tenen A (2017) The effect of autologous adipose derived mesenchymal stem cell therapy in the

ISSN: 2574-1241

DOI: 10.26717/BJSTR.2019.21.003577

Lo Presti Mirco. Biomed J Sci \& Tech Res

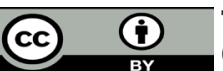

This work is licensed under Creative Commons Attribution 4.0 License

Submission Link: https://biomedres.us/submit-manuscript.php treatment of a large osteochondral defect of the knee following unsuccessful surgical intervention of osteochondritis dissecans-A case study. BMC Musculoskelet Disord 18(1): 298.

46. Spasovski D, Spasovski V, Bascarevic Z, Stojiljkovic M, Vreca M, et al. (2018) Intra-articular injection of autologous adipose-derived mesenchymal stem cells in the treatment of knee osteoarthritis. J Gene Med 20: e3002.

47. Panni AS, Vasso M, Braile A, Toro G, De Cicco A, et al. (2019) Preliminary results of autologous adipose-derived stem cells in early knee osteoarthritis: Identification of a subpopulation with greater response. Int Orthop 43(1): 7-13.

48. Peeters CM, Leijs MJ, Reijman M, van Osch GJ, Bos PK (2013) Safety of intra-articular cell-therapy with culture-expanded stem cells in humans: a systematic literature review. Osteoarthritis Cartilage 21(10): 14651473.

49. Lalu MM, McIntyre L, Pugliese C, Fergusson D, Winston BW, et al. (2012) Canadian Critical Care Trials Group. Safety of cell therapy with mesenchymal stromal cells (SafeCell): a systematic review and metaanalysis of clinical trials. PLoS One 7(10): e47559.

$\begin{array}{ll}\text { BIOMEDICAL } & \text { Assets of Publishing with us } \\ \text { RESEARCHES } & \text { - Global archiving of articles } \\ & \text { - Immediate, unrestricted online access } \\ \end{array}$

